\title{
Eleven years' experience with retinopathy of prematurity: visual results and contribution of cryoablation
}

Ilana Nissenkorn, Isaac Ben Sira, Israel Kremer, Dan D Gaton, Rachelle Krikler, Eliahu Wielunsky, Paul Merlob

\begin{abstract}
We report our 11 years' experience of cryotherapy for retinopathy of prematurity (ROP). Charts of 624 infants weighing under $1250 \mathrm{~g}$ who were admitted to our Neonatal Intensive Care Unit during 1977-87 were reviewed. Three hundred and eighty nine babies survived, and the total ROP prevalence was $57 \cdot 5 \%$. Cryotherapy was applied to $35 \%$. Only one case $(0.25 \%)$ of blindness was detected, and four babies (1\%) had a final visual acuity of less than 20/200 in one eye. The complication rate following cryoablation was very low.
\end{abstract}

Accumulating evidence indicates that retinopathy of prematurity (ROP) is a multifactorial disease, the prevention of which is probably impossible even now with advanced methods of blood-gas monitoring and oxygen restriction..$^{1-6}$ Unfortunately it has reappeared as one of the leading causes of childhood blindness, undoubtedly owing to the increased survival of extremely small babies in modern neonatal intensive care units (NICU) ${ }^{378}$ During the past two decades cryoablation has been more commonly used for the treatment of the acute stages of ROP. ${ }^{69-10}$ Following the results of the International Multicenter Study of ROP the treatment of both affected eyes has been recommended. ${ }^{10}$ We hereby present our 11 years' experience with the treatment of ROP by cryotherapy.

\section{Patients and methods}

Review of the charts of the 624 infants with a birth weight of up to $1250 \mathrm{~g}$ who were under the care of our NICU from January 1977 to April 1987 revealed that, among the 389 babies who survived, 224 developed ROP, 79 of whom underwent cryoablation (Tables 1 and 2). Among the 224 infants found to have ROP 115 had a birth weight of less than $1000 \mathrm{~g}$, whereas 109 had a birth weight of 1000 to $1250 \mathrm{~g}$ : ROP was present in $79.3 \%$ of the former group and in $44.6 \%$ of the latter group (Table 2 ).

Cryoablation was done when confluent fibrovascular proliferations (stage 3 - moderate) occupied more than 3 clock hours in zone I and II with 'plus disease' according to the new classification, ${ }^{11}{ }^{12}$ and in active stage 3 with reference to the old classification of ROP. ${ }^{13}$ The cryotherapy was performed according to a previously published protocol. ${ }^{1+}$ However, in five babies the cryotreatment was performed late in the course of the disease, at stage 4-a and b. One baby was treated in both eyes and four babies in one eye. All these children have remained under regular follow-up, the duration of which ranged from three to 11 years.

The fundoscopic findings of all the ROP patients who were treated during 1977-84, when the old classification was in use, were reclassified by us according to the new classification ${ }^{112}$ and evaluated accordingly. The final best corrected visual acuity was examined in all children up to the age of 5 years by the Ffooks symbols test and in children older than this age, by the standard Snellen visual acuity chart. All children underwent cycloplegic refraction (streak skiascopy) and orthoptic evaluation every six months and were given full optical correction according to their last refraction.

\section{Results}

Cryoablation was carried out on 79 infants (35.3\% of the total). These infants included 56 of the 115 babies (48.7\%) weighing below $1000 \mathrm{~g}$ and 23 of the 109 infants $(21 \cdot 1 \%)$ weighing from 1000 to $1250 \mathrm{~g}$ at birth (Table 2).

The visual results are presented in Tables 3 and 4 . We detected only one case $(0 \cdot 25 \%)$ of bilateral blindness (no perception of light), four eyes (1\%) of four babies with a visual acuity of $<20 / 200$, and 20 infants $(5 \cdot 14 \%)$ with a visual acuity of more than $20 / 80$ in both eyes (Table 3 ). The five babies with a visual acuity of either no perception of light or $<20 / 200$ were treated in stage 4 . Among the total population of neonates $364(93 \cdot 5 \%)$ had normal vision $(>20 / 30)$ (Tables 3 and 4). There were no major intraoperative or postoperative complications among those undergoing cryotherapy in stage 3 (moderate). During the whole period of follow-up no case of late detachment has been observed.

Table 1 Beilinson premature babies' survival rate, 1977-87

\begin{tabular}{llll}
\hline Birth weight $(\mathrm{g})$ & $\begin{array}{l}\text { Noof } \\
\text { children }\end{array}$ & $\begin{array}{l}\text { No of children } \\
\text { survived }\end{array}$ & $\begin{array}{l}\% \\
\text { Survival }\end{array}$ \\
\hline$<1000$ & 324 & 145 & $44 \cdot 7$ \\
$1000-1250$ & 300 & 244 & $81 \cdot 3$ \\
Total $<1250$ & 624 & 389 & $62 \cdot 3$ \\
\hline
\end{tabular}

Table 2 Incidence of ROP among survivors, 1977-87

\begin{tabular}{llllll}
\hline & $\begin{array}{l}\text { No of } \\
\text { children }\end{array}$ & $\begin{array}{l}\text { Nowith } \\
\text { ROP }\end{array}$ & $\begin{array}{l}\text { \% } \\
\text { ROP }\end{array}$ & $\begin{array}{l}\text { No of } \\
\text { cryotreated } \\
\text { children }\end{array}$ & $\begin{array}{l}\% \text { of } \\
\text { cryotreated } \\
\text { children }\end{array}$ \\
\hline$<1000$ & 145 & 115 & $79 \cdot 3$ & 56 & $48 \cdot 7$ \\
$1000-1250$ & 244 & 109 & $44 \cdot 6$ & 23 & $21 \cdot 1$ \\
Total & 389 & 224 & $57 \cdot 5$ & 79 & $35 \cdot 3$ \\
\hline
\end{tabular}

Center, Petah Tiqva and
Tel Aviv University
Sackler School of
Medicine, Israel
Department of
Ophthalmology
I Nissenkorn
I Ben Sira
I Kremer
D D Gaton
Department of
Neonatology
R Krikler
E Wielunsky
P Merlob
Correspondence to:
I Nissenkorn, MD,
Department of
Ophthalmology, Beilinson
Medical Center, Petah Tiqva
49 100, Israel.
Accepted for publication
13 September 1990


Table 3 Visual results among 389 survivors (birth weight $<1250$ g) $1977-1987$

\begin{tabular}{lccll}
\hline $\begin{array}{l}\text { Visual } \\
\text { acuity }\end{array}$ & $\begin{array}{l}\text { No of } \\
\text { babies }\end{array}$ & $\begin{array}{l}\% \text { of } \\
\text { babies }\end{array}$ & $\begin{array}{l}\text { No of } \\
\text { eyes }\end{array}$ & Present retinal findings \\
\hline $\begin{array}{l}\text { No perception } \\
\text { of light }\end{array}$ & 1 & 0.25 & 2 & ROP stage V \\
$\begin{array}{l}\text { (closed funnel) } \\
20 / 800-\end{array}$ & 4 & 1.0 & 4 & $\begin{array}{l}\text { Macular displacement } \\
\text { with traction fold }\end{array}$ \\
$20 / 200-20 / 30$ & 20 & $5 \cdot 14$ & BE $^{\star}$ & $\begin{array}{l}\text { Myopia, peripheral } \\
\text { vitreoretinal changes } \\
\text { None }\end{array}$ \\
$>20 / 30$ & 364 & 93.6 & BE $^{\star}$ & \\
\hline
\end{tabular}

$\star$ Cryotreated at stage 4 .

Table 4 Correlation between visual acuity and age

\begin{tabular}{lcc}
\hline & $\begin{array}{l}\text { No of } \\
\text { preschool } \\
\text { children } \\
(<6 \text { years })\end{array}$ & $\begin{array}{l}\text { No of } \\
\text { school } \\
\text { children } \\
\text { >6 years })\end{array}$ \\
\hline Visual acuity & 1 & 0 \\
No perception of light & 2 & 2 \\
$20 / 800-20 / 200$ & 10 & 10 \\
$20 / 80-20 / 30$ & 172 & 192 \\
$>20 / 30$ & 185 & 204 \\
Total & & \\
\hline
\end{tabular}

\section{Discussion}

A survey on the causes of blindness in Israel, carried out by us seven years ago, revealed that during 1976-81 the main cause of blindness was ROP. ${ }^{8}$ It was obvious that there is direct relationship between the survival rate of very small preterm babies and rate of blindness related to ROP: the higher the survival rate, the higher the rate of blindness. ${ }^{1-7}$

For the treatment of ROP by cryoablation we adopted an approach which was based on early cryotreatment, which means at the stage before 'threshold disease' as defined by the Multicenter Trial of Cryotherapy for ROP. ${ }^{9}$ We diagnosed 'threshold disease' when confluent fibrovascular proliferations were found to occupy more than 3 clock hours, in zone I and II with 'plus disease'. ${ }^{6}{ }^{14}$

According to the results of the Multicenter Trial of Cryotherapy for ROP $^{9}{ }^{10}$ retinal detachment may occur in as high as $23 \%$ of the cryotreated cases. In contrast we found a much lower rate of retinal detachment ( $1 \cdot 25 \%)$ among the cryotreated babies. It should be pointed out that these cases were all treated late in the course of their disease (in stage 4). In our opinion the main reason for this difference is the fact that our treatment was performed at an earlier stage than 'threshold disease' as defined by the Multicenter Trial of Cryotherapy for ROP. ${ }^{9}$

We are aware that ROP has a high incidence of spontaneous resolution in various stages of various degrees, and therefore the condition in some of our babies would probably have regressed without treatment. However, we maintain that earlier treatment may prevent the high rate of retinal detachment after treatment reported by the Multicenter Trial..$^{9}$

With respect to the rate of blindness found among our cryotreated babies, $\mathrm{Phelps}^{37}$ estimated that the rate of blindness due to ROP, among children with a birth weight under $1000 \mathrm{~g}$, is on average $8 \%$. The survival rate of $62 \%$ for the neonates weighing at birth up to $1250 \mathrm{~g}$ and admitted to hospital in our NICU compares favourably with that of modern neonatal units in other countries. ${ }^{8}$ On the basis of the statistical calculations made by Phelps ${ }^{37}$ it may be assumed that without cryotreatment we should have encountered at least 12 cases of bilateral blindness among our whole group of neonates weighing less than $1000 \mathrm{~g}$. In fact, according to our results, among the entire group of neonates only one blind child $(0 \cdot 25 \%)$ and another four children with a visual acuity of $<20 /$ 200 in one eye only were found. Our results do indicate satisfactory visual findings with an extremely low rate of postcryoablation complications. According to the follow-up results presented in this study, we did not find any of the complications following cryoablation described by several authors. ${ }^{10}$ is

In conclusion, from our protocol and results we consider that cryotreatment of ROP should be undertaken before the development of 'threshold disease,' as defined by the Multicenter Trial of Cryotherapy for ROP,' and we agree with the recent conclusion of this trial ${ }^{10}$ that both eyes should be treated when indicated.

1 Kalina RE, Karr DJ. Retrolental fibroplasia: experience over two decades in our institution. Ophthalmology 1982; 89:

2 Gunn TR, Aranda JV, Little J. Incidence of retrolental fibroplasia. Lancet 1978; i: 216-7.

3 Phelps DL. Retinopathy of prematurity: an estimate of vision loss in the United States - 1979. Pediatrics 1981; 67: 924-6.

4 Campbell PB, Bull MJ, Ellis FD, et al. Incidence of retinopathy of prematurity in a tertiary newborn intensive care unit. Arch Ophthalmol 1983; 101: 1686-8.

5 Shohat M, Reisner SA, Krikler R, et al. Retinopathy of prematurity: incidence and risk factors. Pediatrics 1983; 72: $159-63$.

6 Ben-Sira I, Nissenkorn I, Kremer I. Retinopathy of prematurity (ROP): review article. Surv Ophthalmol 1988; 33: turity

7 Phelps DL. Vision loss due to retinopathy of prematurity. Lancet 1981 ; i: 606

8 Nissenkorn I, Wijsenbeek Y, Cohen S, Ben-Sira I. Etiology of blindness in children in Israel in recent years. Acta Concilium Ophthalmologicum 1986; 25: 742-4.

9 Committee for Cryotherapy for retinopathy of prematurity. Multicenter trial of cryotherapy for retinopathy of prematurity (preliminary results). Arch Ophthalmol 1988; 106: 471-9.

10 Committee for Multicenter Trial of Cryotherapy for Retinopathy of Prematurity. Three-month outcome of cryotherapy for retinopathy of prematurity cooperative group. Arch Ophthalmol 1990; 108: 195-204.

11 Committee for the Classification of Retinopathy of Prematurity. An international classification of retinopathy of prity. An international classification of retinopat

prematurity 1 . Arch Ophthalmol $1984 ; 102: 1130-5$.
12 Committee for the Classification of Retinopathy of Prematurity. An international classification of retinopathy of prematurity II. The classification of retinal detachment. Arch Ophthalmol 1987; 105: 906-12.

13 Reese AB, King M, Owens WC. A classification of retrolental fibroplasia. Am $\mathcal{F}$ Ophthalmol 1953; 36: 1333-5.

14 Ben-Sira I, Nissenkorn I, Grunwald E, Yassur Y. Treatment of acute retrolental fibroplasia by cryoablation. $\mathrm{Br} f \mathrm{Oph}$ thalmol 1980; 64: 758-62.

15 Greven CM, Tasman W. Rhegmatogenous retinal detachment following cryotherapy in retinopathy of prematurity. Arch Ophthalmol 1989; 107: 1017-8. 